\title{
The Tail Fibre of Bacteriophage T4 is Sensitive to Proteases at Elevated Temperatures
}

\author{
By PHILIPPE GRANBOULAN† \\ Biozentrum of the University of Basel, Department of Microbiology, Klingelbergstrasse 70 , \\ CH-4056 Basel (BS), Switzerland
}

(Received 12 October 1982; revised 20 January 1983)

\begin{abstract}
Bacteriophage $\mathrm{T} 4$ wild-type is not sensitive to heating at $60^{\circ} \mathrm{C}$. Trypsin at this temperature quickly inactivates the bacteriophage, with first-order kinetics for about the first $60 \mathrm{~min}$. The half-inactivation period is around $15 \mathrm{~min}$. The characteristics of this inactivation reaction have been studied. Inactivation of T4 particles is paralleled by a loss in ability to adsorb to bacteria. SDS-PAGE reveals a 'clipping' of gp 37, the protein of the distal part of the long tail fibres, during the inactivation reaction. gp 37 is the only protein to be modified under these conditions. Mutants have been isolated which resist this modification; they map in gene 37 .
\end{abstract}

\section{INTRODUCTION}

Nucleic acids of all viruses are protected against the environment during the vegetative period of their cycle by shielding surface structures. Escherichia coli bacteriophages, such as T4, are surprisingly resistant to attack by environmental factors, whether physical, chemical or biochemical (for example, proteases) (To et al., 1969). They are much more resistant than the bacteria that support their growth. Hence, it seemed interesting to study the resistance of phage T4 to trypsin for two reasons: to gather data on the fragility/resistance phenomenon, and as a basis for understanding the role of proteases in the life cycle of the virus. The idea that in vitro proteolysis mimics in vivo proteolysis is well documented (Goldberg, 1972; Goldberg \& Dice, 1974; Goldberg \& St John, 1976). T4 wild-type particles are resistant to trypsin; they become sensitive to trypsin only when heated above $60^{\circ} \mathrm{C}$. I shall describe this inactivation reaction, and also the isolation and properties of a resistant mutant that maps in gene 37 , the gene coding for the protein (designated gp 37) of the distal part of the long tail fibres.

\section{METHODS}

Genetic designations. am, amber; ptr, resistant to inactivation by trypsin at $60^{\circ} \mathrm{C}$; $t$, thermosensitive; wt, wildtype; gp, gene product.

Chemicals. Enzymes : trypsin (Serva) from bovine pancreas, TPCK (L-1-tosylamide-2-phenylethyl chloromethyl ketone) treated, $40 \mathrm{U} \mathrm{ml}^{-1}$ (trypsin crude extract, P. H. Stehelin, Basel, Switzerland, was used for screening experiments); $\alpha$-chymotrypsin from bovine pancreas, type II, Sigma; trypsin soya bean inhibitor no. 24020 , Merck; pronase, lyophilized, B grade, Calbiochem; deoxyribonuclease, crude extract, Sigma. Other chemicals: lactose, Siegfried, Zofingen; sucrose, ultrapure, Schwartz/Mann; $\left[{ }^{35}\right.$ S $]$ methionine was a gift of K. Suda; $\left[{ }^{3} \mathrm{H}\right]$ thymidine was obtained from Amersham.

General techniques. The methods used for bacterial and phage culture, sucrose gradient centrifugation, SDSPAGE and autoradiography, and electron microscopy have been described (Adams, 1959; Showe et al., 1976).

Proteolysis with trypsin: standard conditions. Phage stocks at concentrations from $10^{12}$ to $10^{8}$ phage $\mathrm{ml}^{-1}$ were diluted 1 to 10 in phosphate buffer in the presence of $\mathrm{Mg}^{2+}\left(10^{-3} \mathrm{M}\right)$ (Showe et al., 1976) and trypsin $\left(100 \mu \mathrm{g} \mathrm{mi}^{-1}\right)$. The trypsin stock solution was kept at $4^{\circ} \mathrm{C}$ at $1000 \mu \mathrm{g} \mathrm{ml}^{-1}$ in $10^{-3} \mathrm{M}-\mathrm{HCl}$ solution : activity was preserved for several weeks. For inactivation, the suspension was heated to $60^{\circ} \mathrm{C}$. At various times the suspension was agitated for about $10 \mathrm{~s}$ and a sample $(50$ to $100 \mu \mathrm{l})$ was removed and cooled to $20^{\circ} \mathrm{C}$.

$\dagger$ Present address: Department of Molecular Biology and Microbiology, Tufts University School of Medicine, 136 Harrison Avenue, Boston, Massachusetts 02111, U.S.A. 
Table 1. Bacterial and phage strains

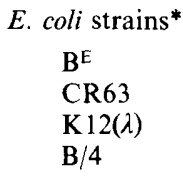

Phage T4 mutants used in crosses to locáte the ptr mutant*

$\begin{array}{cl}\text { Gene } & \text { Mutant } \\ \mathrm{r}^{\mathrm{II}} & \mathrm{r} 219 \\ 5 & \text { am B } 256 \\ 10 & \text { am B 255 } \\ 23 & \text { am H } 32 \\ 27 & \text { am N 120 } \\ 57 & \text { am E 198 } \\ 31 & \text { am N } 54 \\ 33 & \text { am N 134 } \\ 37 & \text { am B 280 } \\ 43 & \text { am B 22 } \\ 44 & \text { am N } 82 \\ 49 & \text { am E 272 }\end{array}$

Relevant properties

Non-permissive for amber

Permissive for amber Non-permissive for $\mathrm{r}^{\mathrm{II}}$ Resistant to T4

\begin{tabular}{|c|c|c|}
\hline \multicolumn{3}{|c|}{ Other phage $\mathrm{T} 4$ mutants } \\
\hline Gene & Mutant & Source $†$ \\
\hline 23 & $a m \mathrm{H} 11$ & 1 \\
\hline 23 & am $\mathrm{H} 32$ & 1 \\
\hline 23 & ts $\mathrm{H} 86$ & 1 \\
\hline 36 & $a m \mathrm{E} 1$ & 1 \\
\hline 37 & $a m \mathbf{N} 52$ & 1 \\
\hline 37 & am B 34 & 2 \\
\hline 37 & $a m$ B 280 & 1 \\
\hline 37 & am NG 187 & 3 \\
\hline 37 & am NG 475 & 3 \\
\hline 38 & am B 262 & 1 \\
\hline 38 & $a m$ A 470 & 2 \\
\hline 38 & $a m \mathrm{H} 41$ & 3 \\
\hline
\end{tabular}

* All from this laboratory.

† Sources: 1, this laboratory; 2, Professor R. Epstein, Département de Biologie Moléculaire, 30, quai Ernest Ansermet, CH 1211 Genève 4, Switzerland; 3, Dr W. B. Wood, University of Colorado, Boulder, COLO 80309, U.S.A.

Selection of ts revertants of am mutants: screening of single plaques for trypsin resistance. A typical experiment is described. Double mutants ptr-am $x$ ( $x$ stands for the mutant designation) (Table 1) were plated at $10^{8}$ per plate on $E$. coli $\mathrm{B}^{\mathrm{E}}$ and incubated at $32^{\circ} \mathrm{C}$ overnight. Single plaques were checked for their $t s$ character. Samples of the $t s$ plaques were suspended in $1 \mathrm{ml}$ of phosphate buffer containing trypsin $\left(100 \mu \mathrm{g} \mathrm{ml}^{-1}\right)$ and treated with chloroform. A drop of this suspension was laid on a lawn of bacteria; the suspension was further incubated at $60{ }^{\circ} \mathrm{C}$ for $1 \mathrm{~h}$ and then spot tested again. Comparison of the lysis before and after incubation allowed resistant plaques to be detected. Plaques were purified, and lysates were made from purified plaques and checked for trypsin resistance.

Complementation. Exponentially growing bacteria in medium M9 AA (Showe et al., 1976) at $2 \times 10^{8}$ bacteria $\mathrm{ml}^{-1}$ were infected and 9 min later superinfected to a total m.o.i. of 10 . After $1 \mathrm{~h}$, the culture was lysed with chloroform. The input ratios and non-permissive conditions (strain and temperature) are described for each experiment. All crosses were made under the same conditions.

Radioactive labelling. Fresh overnight cultures were diluted 1 to 100 in M9 medium and grown to a concentration of $2 \times 10^{8} \mathrm{ml}^{-1}$. Labelling was done in a second subculture in M9 medium supplemented with $10^{-4}$ $\mathrm{M}-\mathrm{MgSO}_{4}$ for methionine labelling, or with $10^{-2} \%$ Casamino acids (Difco) for thymidine labelling. Timing and concentrations are indicated for each experiment.

\section{RESULTS}

\section{Effect of trypsin and temperature on T4 wild-type phage infectivity}

Bacteriophage T4 wild-type is not sensitive to heating at $60{ }^{\circ} \mathrm{C}$ (Arscott \& Goldberg, 1969; Kao \& McClain, 1980) or to trypsin below this temperature. However, it was rapidly inactivated in the presence of trypsin at $60^{\circ} \mathrm{C}$. The inactivation followed first-order kinetics (Fig. 1) with a first-order rate constant calculated for 30 different single plaques after 30 min incubation of $k=$ $0.172 \mathrm{~min}^{-1}$ (S.D. $0.03 \mathrm{~min}^{-1}$ ). Without trypsin, there was a slow inactivation, with some variation from experiment to experiment, with $k$ about $0.003 \mathrm{~min}^{-1}$. Besides the fluctuation of the response of individual plaques to trypsin treatment, there seemed to be some variation of susceptibility from stock to stock.

During inactivation the morphology of the plaques became heterogeneous and more and more plaques were minute. First-order kinetics stopped after about $1 \mathrm{~h}$; about one phage in $10^{4}$ remained viable. Curves were of the same type at $\mathrm{pH} 5$ (at this $\mathrm{pH}$ long tail fibres are in the up position: Kellenberger et al., 1965). Inactivation curves were the same for sucrose-purified stocks as for crude lysates. 


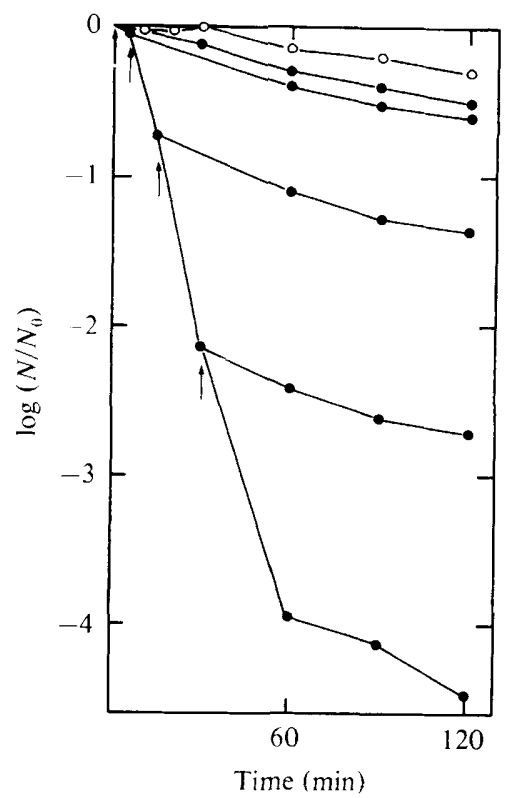

Fig. 1. Trypsin inactivation of phage. Trypsin inactivation was carried out both under the standard conditions and after addition of soya bean trypsin inhibitor $\left[1.2 \mathrm{mg}(\mathrm{mg} \text { enzyme })^{-1}\right]$ at $0,5,15$ and $30 \mathrm{~min}$ after the beginning of inactivation (arrows). The figure is a semi-logarithmic plot of the surviving fraction as a function of time. Wild-type; $O$, ptr mutant.

\section{Selection of a resistant mutant}

It seemed interesting to isolate a mutant resistant to this inactivation, and to investigate its phenotype and its genetic localization. Such a phage could not be obtained by single-step selection: several successive cycles of proteolysis were required. I propose to call this variant $p t r$.

Escherichia coli was grown in M9 AA medium (Showe et al., 1976) to a concentration of $2 \times$ $10^{8}$ bacteria $\mathrm{ml}^{-1}$. After low-speed centrifugation, the bacteria were resuspended at $2 \times$ $10^{9} \mathrm{ml}^{-1}$ in phosphate buffer and aerated for $15 \mathrm{~min}$. Chymotrypsin-treated phage were adsorbed to these bacteria at an m.o.i. of about 0.01 or $0 \cdot 1$, diluted 1 to 10 in M9 AA and aerated for $2 \mathrm{~h}$. The chloroform-treated lysate was treated in the same way and submitted to another cycle of growth. After seven cycles, the fraction of survivors was $40 \%$ and ptr mutants were easily found by screening isolated plaques for resistance. Similar selections were performed on T4 strain $23(a m \mathrm{H} \mathrm{32})$ grown on $E$. coli CR63 at $37^{\circ} \mathrm{C}$ and on T4 strain 23 ( $t s \mathrm{H} \mathrm{86)}$ grown on $E$. coli $\mathrm{B}^{\mathrm{E}}$ at $32^{\circ} \mathrm{C}$. am $\mathrm{m}^{+}$and $t \mathrm{~s}^{+}$derivatives were subsequently isolated by crossing. In all experiments, the behaviour of these two mutants was the same.

The ptr mutants resist trypsin inactivation: they show a slow inactivation, exponential for at least $2 \mathrm{~h}$ with $k=10^{-3} \mathrm{~min}^{-1}$ (Fig. 1). This rate of inactivation was about the same as that of the wild-type without trypsin at $60^{\circ} \mathrm{C}$, but it seemed more reproducible : inactivation of a ptr mutant seemed a better reference for a definition of wild-type inactivation than the spontaneous inactivation without trypsin of the wild-type. The titre of $p t r$ strains sometimes increased at the beginning of the inactivation. This effect was found with crude lysates.

Characterization of the inactivation reaction: comparison between the wild-type and a ptr mutant

To investigate the reliability and the accuracy of the test, the same isolated single plaque was counted twice. Fifty single plaques were collected at random from the offspring of coinfection by wild-type and a ptr mutant (at an m.o.i. of 5 for each phage). For each single plaque, counting was performed after two different periods of inactivation, $30 \mathrm{~min}$ and $60 \mathrm{~min}$. In the regression graph of $k_{60 \mathrm{~min}}$ versus $k_{30 \mathrm{~min}}$ (not shown), the points were grouped in two clusters: 21 in the resistant zone, 29 in the sensitive zone. In spite of the highly significant difference between the two clusters (sensitive and resistant) the reproducibility inside each cluster was poor (correlation coefficient $r=0.136$ for the sensitive and $r=0.028$ for the resistant). 
Table 2. Comparison between trypsin and pronase inactivation of phages

Inactivation was carried out under the standard conditions $\left(100 \mu \mathrm{g}\right.$ trypsin $\left.\mathrm{ml}^{-1}\right)$ at $60^{\circ} \mathrm{C}$ and compared with pronase inactivation $\left(10 \mu \mathrm{g} \mathrm{ml}^{-1}\right)$ : no significant difference was observed.

Fraction of phage surviving after incubation time (min) shown:

\begin{tabular}{lllllllll}
\multirow{2}{*}{ Phage } & Protease & 10 & 20 & 30 & 45 & 60 & 90 & 120 \\
ptr & Trypsin & 1.5 & 0.8 & 0.6 & 0.6 & 0.5 & 0.8 & 0.7 \\
& Pronase & 0.7 & 0.7 & 0.7 & 0.5 & 0.5 & 0.2 & 0.5 \\
wt & Trypsin & 0.3 & 0.06 & 0.01 & $9 \times 10^{-4}$ & $3 \times 10^{-4}$ & $7 \times 10^{-5}$ & $9 \times 10^{-5}$ \\
& Pronase & - & 0.08 & 0.01 & $8 \times 10^{-4}$ & $3 \times 10^{-4}$ & $3 \times 10^{-5}$ & $6 \times 10^{-5}$
\end{tabular}

\section{Table 3. Reversibility of heat treatment of phage}

Several phage stocks were treated for $1 \mathrm{~h}$ at $60^{\circ} \mathrm{C}$ with and without trypsin, and at $37^{\circ} \mathrm{C}$ with trypsin. Phages exposed to high temperature recovered their infectivity after cooling.

\begin{tabular}{lccccc} 
& \multicolumn{4}{c}{ Fraction of phage surviving after treatment } \\
\cline { 2 - 6 } & $\begin{array}{c}\text { ptr } \\
\text { (sucrose- } \\
\text { purified) }\end{array}$ & $\begin{array}{c}\text { (fresh } \\
\text { lysate) }\end{array}$ & $\begin{array}{c}\text { wt } \\
\text { (old } \\
\text { lysate) }\end{array}$ & $\begin{array}{c}\text { wt } \\
\text { (sucrose- } \\
\text { purified) }\end{array}$ & $\begin{array}{c}37 \text { (am B 280) } \\
\text { (fresh } \\
\text { lysate) }\end{array}$ \\
$37^{\circ} \mathrm{C}$ with trypsin & 0.84 & 1.22 & 0.91 & 0.79 & 1.09 \\
$60^{\circ} \mathrm{C}$ without trypsin & 0.51 & $0 \cdot 51$ & 0.37 & 0.41 & 0.27 \\
$60^{\circ} \mathrm{C}$ with trypsin & 0.60 & $4 \times 10^{-4}$ & $6 \times 10^{-5}$ & $10^{-4}$ & $3 \times 10^{-4}$
\end{tabular}

\section{Table 4. Effect of temperature on phage inactivation}

Samples of a wt stock were incubated with trypsin $\left(100 \mu \mathrm{g} \mathrm{ml}^{-1}\right)$ at different temperatures. The firstorder rate constants $(k)$ are given.

$$
\begin{array}{llllllll}
\multicolumn{1}{c}{\text { Temp. } .} & 37^{\circ} \mathrm{C} & 47^{\circ} \mathrm{C} & 55^{\circ} \mathrm{C} & 60^{\circ} \mathrm{C} & 65^{\circ} \mathrm{C} & 75^{\circ} \mathrm{C} & 80{ }^{\circ} \mathrm{C} \\
k_{\text {initial }}\left(\mathrm{min}^{-1}\right) & <10^{-4} & <10^{-4} & 10^{-3} & 0.16 & 0.70 & 1.00 & 1.60 \\
k_{90 \text { min }}\left(\mathrm{min}^{-1}\right) & 2 \times 10^{-4} & 8 \times 10^{-4} & 10^{-2} & 0.95 & 0.12 & 0.12 & 0.13
\end{array}
$$

The reaction was not specific for the protease used: inactivation curves for wild-type phage were the same for trypsin as for pronase, i.e. for a highly specific enzyme and for an enzyme of low specificity. Conversely, a ptr mutant was resistant to both enzymes (Table 2).

Inactivation was not stopped by dilution of the reaction mixture at $60{ }^{\circ} \mathrm{C}$ (data not shown). Lowering the temperature to room temperature stopped the inactivation as testified by the inactivation curves. Another way to stop the reaction was the use of the soya bean trypsin inhibitor: addition of $1.2 \mathrm{mg}$ of inhibitor per $\mathrm{mg}$ of enzyme stopped the inactivation immediately (Fig. 1). Trypsin inhibitor was always used when proteins had to be analysed by SDS-PAGE.

There was a strong transition effect at $60^{\circ} \mathrm{C}$ : below this temperature, practically no inactivation was observed. Since heating without enzyme did not inactivate the virus, inactivation works in two steps: the first a reversible transition necessary for the second, the irreversible inactivation by trypsin (Table 3 ). When the temperature of the reaction was increased progressively to $80^{\circ} \mathrm{C}$, the initial velocity of inactivation increased; but the final extent of inactivation was not very much changed, as shown by the values of $k$ at $90 \mathrm{~min}$ (Table 4).

Maximum inactivation was obtained with 100 or $1000 \mu \mathrm{g}$ trypsin $\mathrm{ml}^{-1}$. At lower concentrations, the efficiency decreased very quickly, and $1 \mu \mathrm{g} \mathrm{ml}^{-1}$ was practically without effect (data not shown). A standard concentration of $100 \mu \mathrm{g} \mathrm{ml}{ }^{-1}$ was used. Thermal 


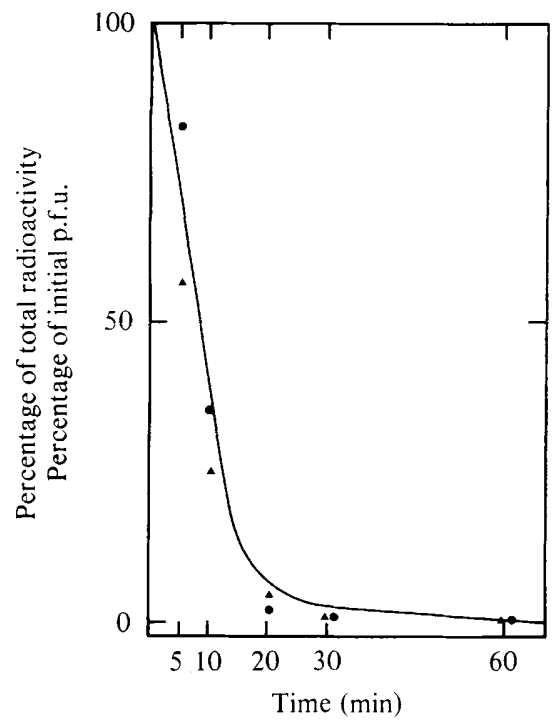

Fig. 2. Kinetics of loss of adsorbability of phage particles during trypsin treatment. After trypsin treatment for $0,5,20,30$ and $60 \mathrm{~min},\left[{ }^{3} \mathrm{H}\right]$ thymidine-labelled $\mathrm{r}^{\mathrm{II}}$ phage were adsorbed at $37^{\circ} \mathrm{C}$, at an m.o.i. of 0.2 to $E$. coli $\mathrm{K} 12(\lambda)$ at a concentration of $5 \times 10^{7}$ bacteria $\mathrm{ml}^{-1}$. After 10 and $20 \mathrm{~min}$, adsorption was stopped by dilution followed by low-speed centrifugation. Samples from the pellet and the supernatant were counted in a scintillation counter. The average results of 10 and 20 min adsorption are expressed as radioactivity in the pellet as a percentage of total recovery. Unspecific adsorption, as measured on $E$. coli $\mathrm{B} / 4$, was subtracted for each point. $\Delta$, p.f.u.; $\boldsymbol{O}$, radioactivity.

inactivation or autodigestion of trypsin could not explain why the reaction did not proceed, since addition of fresh enzyme after $1 \mathrm{~h}$ did not restart it (data not shown).

Inactivation affects adsorbability. Studies of the adsorption of radioactively labelled phages are hindered in two ways: first, only some of the physical particles adsorb to bacteria; second, in our particular case, incubation at $60^{\circ} \mathrm{C}$ could lead to non-specific adsorption. Hence, correction has been made for these two factors by considering only the particles able to adsorb before any treatment and by subtracting the background of non-specific adsorption as measured on $E$. coli B/4 (which is resistant to T4). After correction of the raw data, there is good agreement between the kinetics of p.f.u. inactivation and the kinetics of loss of the adsorption properties, at least during the first $30 \mathrm{~min}$ of trypsin treatment (Fig. 2).

It has been demonstrated that glucose and glucose-containing oligosaccharides with a $(1 \rightarrow 3)$ $\alpha$-glucose-glucose linkage hinder the adsorption of phages to bacteria; this is taken as a demonstration of the kinship of this sugar with a bacterial receptor component (hence the adsorption of phage in the presence of lactose and the non-adsorption in the presence of sucrose : Dawes, 1975). The effect of sucrose on trypsin inactivation was therefore studied. Sucrose inhibited trypsin inactivation at the same concentration that it inhibited adsorption to bacteria; lactose did not inhibit (Table 5). This suggests that the target site for inactivation is not far from the specific adsorption site at the tip of the long tail fibres.

Two more instances showed the loss of ability to adsorb to bacteria: quantitative electron microscopy showed that, after inactivation, phages no longer adsorb to bacteria (M. Wurtz, personal communication), and the tip of gp 37, which is known to be the adsorption-specific region, was 'clipped' during inactivation (see below).

These experiments indicate that, during the inactivation reaction, the wild-type phage loses the ability to adsorb to bacteria.

Effect of trypsin on phage proteins. Inactivation was paralleled by partial proteolysis of the tail fibre protein gp 37: SDS-PAGE demonstrated the progressive 'clipping' of this protein 


\section{Table 5. Effect of sucrose on phage inactivation}

Trypsin inactivation was carried out under the standard conditions at various concentrations of sucrose. In a parallel experiment, the action of the same concentrations of sucrose on the adsorption to bacteria was checked: phage suspensions were incubated for $10 \mathrm{~min}$ at $37^{\circ} \mathrm{C}$ with $10^{9}$ bacteria $\mathrm{ml}^{-1}$, then centrifuged at low speed. The fraction of phage surviving is given for the trypsin treatment experiments and the fraction of phage in the supernatant for the adsorption experiments.

\begin{tabular}{|c|c|c|c|c|c|c|c|c|}
\hline $\begin{array}{l}\text { Concn of lactose } \\
\text { or sucrose }(\%, w / v)\end{array}$ & 0 & 0.75 & $1 \cdot 5$ & $2 \cdot 25$ & 3 & 6 & $7 \cdot 5$ & 15 \\
\hline \multicolumn{9}{|l|}{ Sucrose } \\
\hline wt: trypsin treatment $(30 \mathrm{~min})$ & $2 \times 10^{-3}$ & 0.02 & 0.06 & $0 \cdot 18$ & $0 \cdot 3$ & 0.6 & $0 \cdot 8$ & 0.9 \\
\hline $\mathrm{wt}:$ trypsin treatment $(60 \mathrm{~min})$ & $10^{-3}$ & $2 \times 10^{-3}$ & $5 \times 10^{-3}$ & 0.02 & $0 \cdot 1$ & 0.6 & 0.5 & 0.9 \\
\hline ptr: trypsin treatment $(30 \mathrm{~min})$ & & & & & & & & $1 \cdot 3$ \\
\hline ptr: trypsin treatment $(60 \mathrm{~min})$ & & & & & & & & $1 \cdot 0$ \\
\hline wt: adsorption & 0.01 & 0.04 & 0.01 & 0.06 & 0.03 & 0.09 & 0.44 & 0.42 \\
\hline ptr: adsorption & $5 \times 10^{-3}$ & 0.04 & 0.08 & 0.01 & $0 \cdot 2$ & $0 \cdot 6$ & $0 \cdot 7$ & 0.6 \\
\hline \multicolumn{9}{|l|}{ Lactose } \\
\hline $\begin{array}{l}\text { wt: trypsin treatment }(60 \mathrm{~min}) \\
\text { wt: adsorption }\end{array}$ & $\begin{array}{c}10^{-4} \\
2 \times 10^{-3}\end{array}$ & $10^{-4}$ & $10^{-4}$ & $10^{-4}$ & $7 \times 10^{-5}$ & $2 \times 10^{-4}$ & $10^{-4}$ & $\begin{array}{l}4 \times 10^{-3} \\
4 \times 10^{-3}\end{array}$ \\
\hline
\end{tabular}

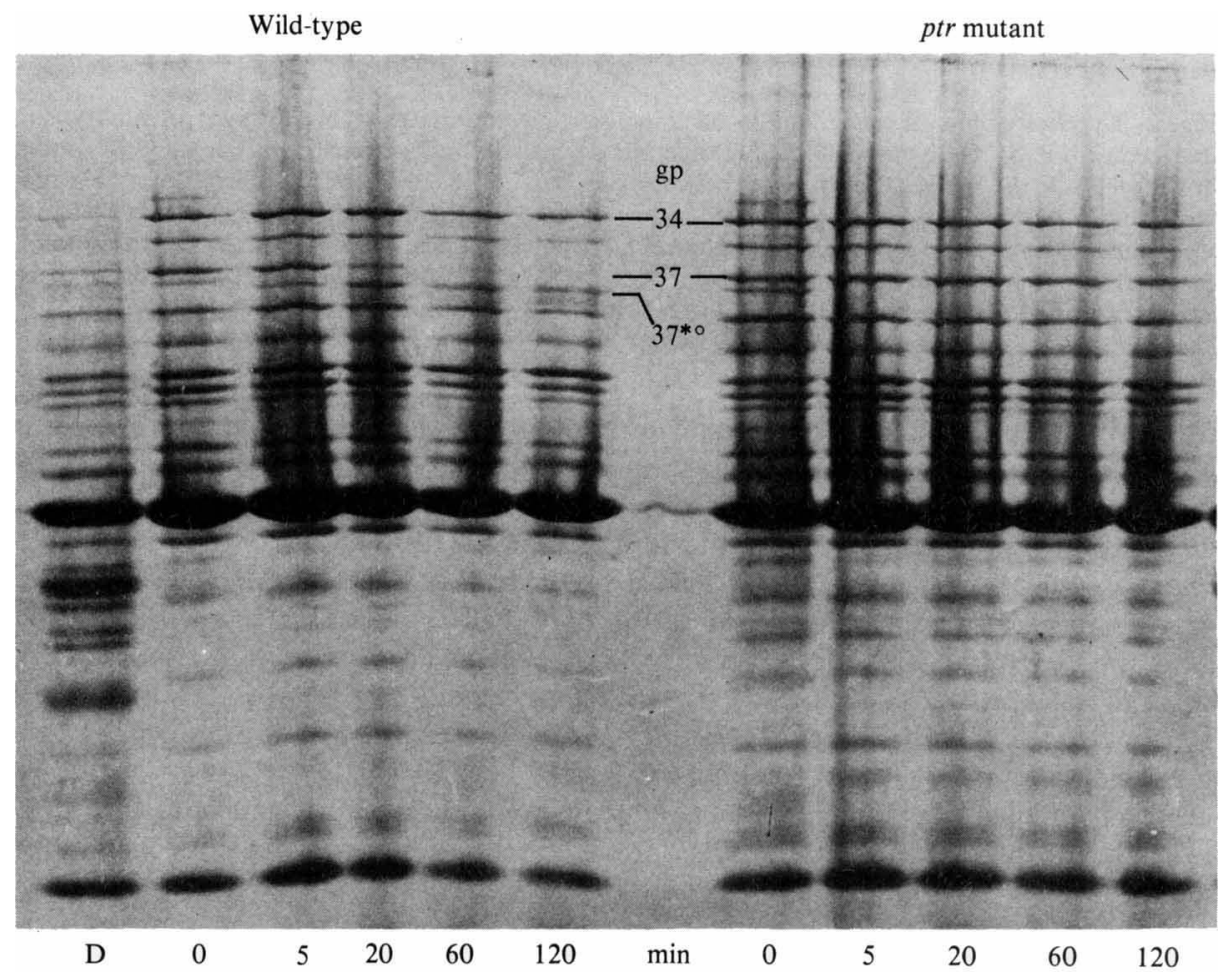

Fig. 3. Trypsin proteolysis of phage particles demonstrated by SDS-PAGE. Sucrose-purified phage particles were treated with trypsin under the standard conditions for 5, 20,60 and $120 \mathrm{~min}$. The proteins were separated by SDS-PAGE [running gel $10 \%(\mathrm{w} / \mathrm{v})$ acrylamide] and stained with Coomassie blue. Track D shows the effects of omitting trypsin and adding $5 \mu \mathrm{g}$ crude DNAase (which contains a protease) $\mathrm{ml}^{-1}$. The gp 37 band of the wild-type disappeared, whereas the corresponding band of the ptr mutant did not. (Trailing was due to the absence of DNAase.)

during incubation with trypsin at $60{ }^{\circ} \mathrm{C}$ (Fig. 3). The gp 37 band was the only one that was degraded in the wild-type but was not altered in the ptr mutant. This clipping gave rise to a fragment about 4-7 kilodaltons smaller than the original gp 37 band, taking the other T4 bands as a calibrating reference. I propose the notation $37^{* \circ}$ for this band. The degradation of $37^{* \circ}$ was slow. SDS-PAGE of trypsin digests was made possible only by using soya bean trypsin 


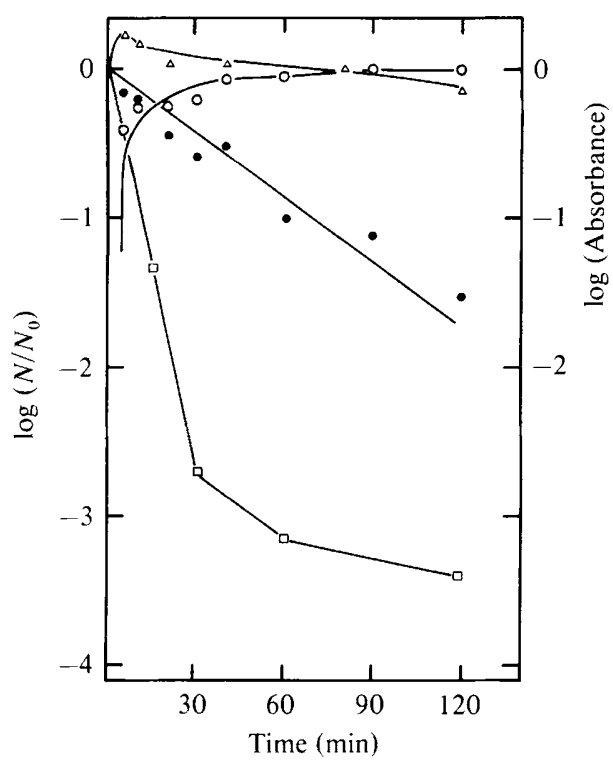

Fig. 4. Kinetics of gp 37 degradation. Phage particles were labelled by adding $\left[{ }^{35}\right.$ S $]$ methionine at a final concentration of $5 \mu \mathrm{Ci} \mathrm{ml}^{-1} 20 \mathrm{~min}$ after infection. The cultures were supplemented with $1 \%$ magnesium sulphate $2 \mathrm{~min}$ before harvesting, at $90 \mathrm{~min}$. Phage particles were purified on sucrose gradients and treated with trypsin under the standard conditions. Proteins were separated by SDSPAGE, detected by autoradiography, and quantified by densitometry. The figure is a semi-logarithmic plot of the densitometric measurements of the gp 37 band. Since no gp $37^{* \circ}$ can be seen at $t=0$, the value at $120 \mathrm{~min}$ has been taken as the standard for this band. The wild-type gp 37 disappeared with first-order kinetics with average $k=0.045 \mathrm{~min}^{-1}$. The gp 37 of the ptr mutant was not digested. Densitometry: , gp 37 of wild-type; $\bigcirc$, gp $37^{* \circ}$ of wild-type; $\triangle$, gp 37 of ptr mutant. The logarithm of the fraction of surviving wild type phages is also shown ( $\square$ ).

inhibitor, since the trypsin proteolysis was not stopped by dilution and since the enzyme remains active in the presence of SDS (Cleveland et al., 1977). The clipping was found with crude lysates as well as with particles purified on sucrose gradients, and it was found with unlabelled preparations (Fig. 3) as well as with radioactive ones (Fig. 4). Clipping could also be seen on long tail fibres purified on sucrose gradients: in this case, the gp 34 band was degraded in the same way in wild-type and in ptr particles (data not shown). One can assume that a sensitive site is unmasked in isolated fibres, but masked when these fibres are attached to the base plate by their proximal end, which is made of gp 34 .

Degradation of gp 37 was measured by densitometry using a Joyce Loebl spectrophotometer. Semi-logarithmic plots show that the results could fit with first-order inactivation kinetics; the average $k$ for the values in Fig. 4 is $k=0.045 \mathrm{~min}^{-1}$ (S.D. 0.018). Within the limits of accuracy of the measurements, I have no evidence for a shoulder at the origin of the curve. Taking these two results at face value, there would be no precursor-product relationship between the two phenomena: clipping and p.f.u. inactivation are two distinct reactions. SDS-PAGE of the ptr mutant demonstrated that gp 37 was stable during trypsin incubation; however, some protein bands disappeared during the incubation of purified particles of both wild-type and ptr strains. As infectivity was preserved in the ptr mutant, these bands can be ascribed to dispensable proteins (Fig. 3). Electron microscopy showed the clipping of the tip of the long tail fibres after treatment of the wild type; this clipping was not seen after treatment of a ptr mutant (M. Wurtz, personal communication).

Demonstration that the mutation lies in gene 37

Complementation mapping. Attempts to complement a ptr mutant with the wild-type failed, because the inactivation curve could not be distinguished from that of the ptr mutant alone (Fig. 6). The mixing of the two lysates gave the same result (Fig. 5). 


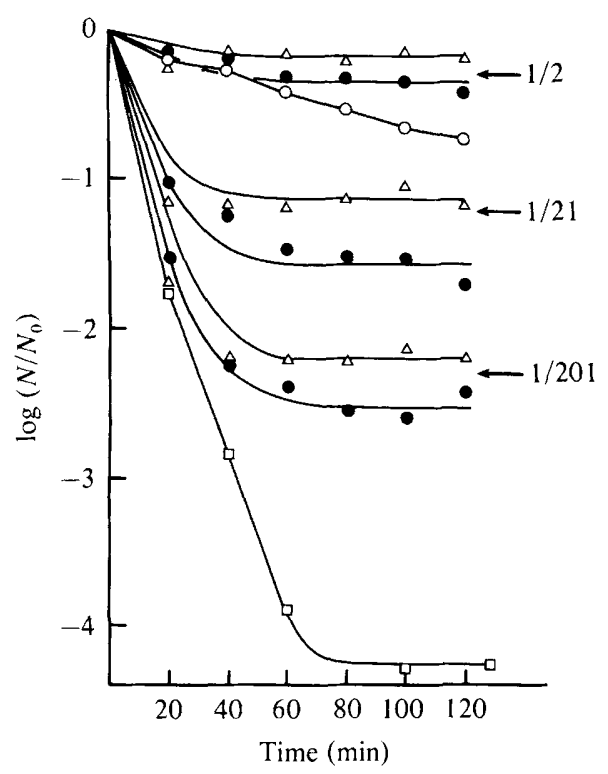

Fig. 5. Complementation of ptr phage by wild-type phage. The ptr strain was complemented by the wild-type at a constant m.o.i. of 10 . The ratios of ptr input to total input were $1 / 2,1 / 21$, and $1 / 201$. On the other hand, ptr and wild-type were mixed in the same proportion: 1/2,1/21, and 1/201. Trypsin inactivation was carried out under the standard conditions for $20,40,60,100$ and $120 \mathrm{~min}$. A semilogarithmic plot of the surviving fraction as a function of incubation time is presented. The results are plotted after subtraction of the logarithm of the average inactivation of the relevant ptr control. The horizontal part of each curve is the average of the last three points. The arrows point to the position of the plateau expected from theoretical considerations. $\bigcirc$, ptr control; $\square$, wild-type control, corrected; , complemented phages; $\triangle$, mixture of phages of the two phenotypes.

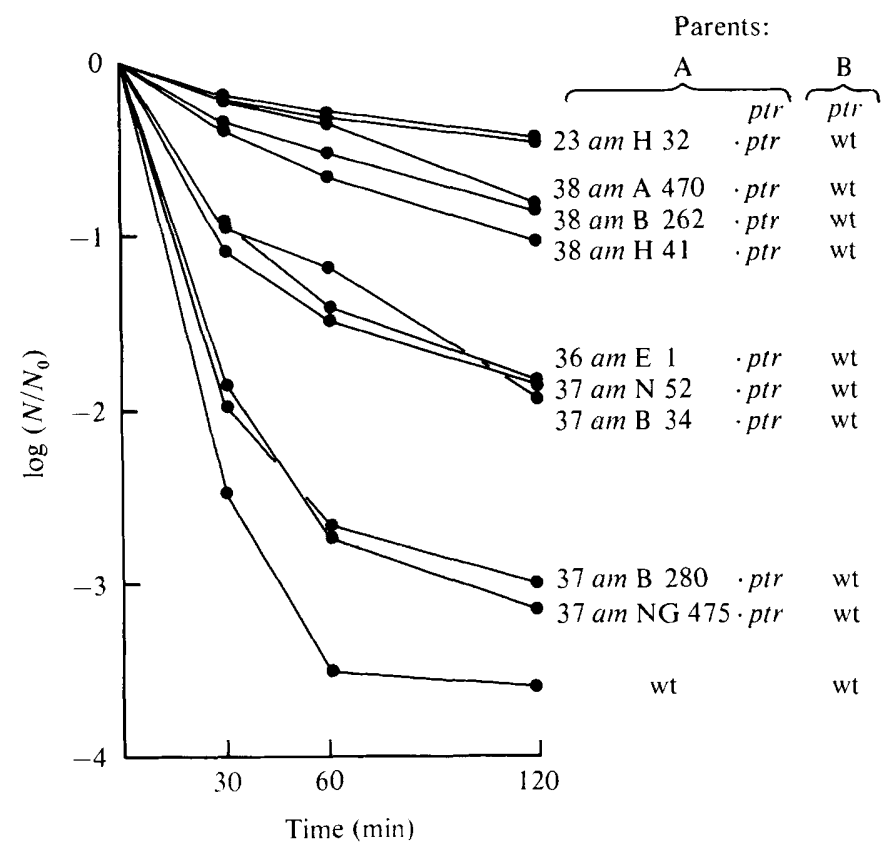

Fig. 6. Complementation of amber double mutants by wild-type. Double mutants ptr-am $x$ (the amber mutation being located in genes $36,37,38$ ) were complemented by wild-type $\mathrm{T} 4$ on the non-permissive strain $E$. coli $\mathrm{B}^{\mathrm{E}}$. The progeny were examined for trypsin sensitivity as described previously. Each point is the average of three experiments. 
Rough localization by crossing. The ptr mutant was crossed with amber mutants scattered along the T4 genome. After intermediate culture at low multiplicity, the genotype of 100 single isolated plaques was examined in two different ways: (a) trypsin treatment before plaque isolation and further determination of the $a \mathrm{~m} / \mathrm{am}^{+}$genotype by spot tests; (b) isolation of single plaques, followed by resuspension in liquid medium and direct determination for each plaque, by trypsin treatment of each suspension, of the am/am ${ }^{+}$genotype and of the $p t r / w t$ genotype. These two experiments were performed on the progeny of 11 crosses (Table 1). The smallest number of recombinants of the type ptr-am $\left(6 \%\right.$ of the parent ptr-am $\left.{ }^{+}\right)$was obtained from the $p t r \times 37$ (am B 280) cross. This figure differs significantly both from the expected average result $(50 \%)$ and from the measured average (61\% and $40 \%$, respectively). Thus the ptr mutation is located close to gene 37 .

A more accurate location of the mutation in relation to gene 37 needed a different approach, which was to complement wild-type phages by double-mutant phages carrying $p t r$ and different am mutations. The rationale of the experiment is that if the two mutations are located in the same gene, the ptr character cannot be expressed, since the whole gene product is not made.

Isolation of double mutants. Mutants $36(\mathrm{am} \mathrm{E} \mathrm{1)} \mathrm{and} 37$ ( $\mathrm{am} \mathrm{B} \mathrm{280)}$ were by-products of the preceding experiment. In the other crosses, single am mutants in the tail fibre region were

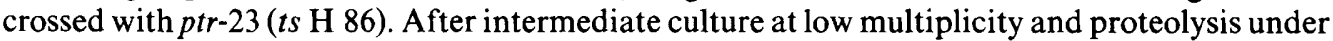
the standard conditions, the progeny were plated on E. coli CR63 (permissive for amber) and incubated at $42^{\circ} \mathrm{C}$. Single plaques were collected and tested for their am/am ${ }^{+}$and $\mathrm{ptr} / \mathrm{wt}$ character by spot tests as described above. The following double mutants were constructed: $p t r$ and 37 ( $\mathrm{am} \mathrm{N} \mathrm{52);} 37$ ( $\mathrm{am} \mathrm{B} \mathrm{34);} 37$ ( $\mathrm{am}$ NG 475); 38 ( $\mathrm{am} \mathrm{B} \mathrm{262);} 38$ (am A 470); $38(\mathrm{am} \mathrm{H} \mathrm{41)}$ ). I obtained only one ptr-37 (am NG 475) mutant after screening 150 plaques, and no ptr-37 (am NG 187) mutants, despite examining 800 single plaques. Neither was such a strain isolated from direct selection after repeated trypsin treatment of the original amber strain.

Complementation of the wild-type by double mutants. Complementation was done in the usual way. The result of the trypsin treatment of the offspring permitted classification of the complemented phages into three groups (Fig. 6):

1. as sensitive as the wild-type: 37 ( $\mathrm{am} \mathrm{B} \mathrm{280);} 37$ (am NG 475)

2. as resistant as ptr: $38(\mathrm{am} \mathrm{B} \mathrm{262);38(am} \mathrm{A} \mathrm{470);} 38(a m$ H 41)

3. showing intermediate behaviour: 36 ( $a m \mathrm{E} 1) ; 37$ ( $\mathrm{am} \mathrm{B} \mathrm{34);} 37$ ( $\mathrm{am} \mathrm{N} \mathrm{52)}$.

Taking into account the well-documented polarity of genes 36, 37 and 38 of T4 (Beckendorf, 1973; King \& Laemmli, 1971; Stahl et al., 1970; Terzaghi, 1971; Ward \& Dickson, 1971) the above data are only compatible with two explanations: that the ptr mutation maps in gene 37 or that the ptr mutation maps in a new gene located between genes 37 and 38 .

ptr does not map in a new gene between genes 37 and 38 . To eliminate the possibility that an as yet unidentified gene between 37 and 38 might carry the ptr mutation and be unexpressed owing to the polarity 37,38 , I isolated revertants of the am in gene 37 which were $t s$. NG 475 gave the same response as am or as the ts revertant (Fig. 7). This eliminates the possibility that the expression of a new gene may be hindered by an amber mutation in gene 37 because of the polarity of the operon.

Tentative fine localization inside gene 37. To obtain better information on the location of ptr, I made three-factor crosses of ptr-37 ( $\mathrm{am} x) \times 38(\mathrm{am} \mathrm{B} \mathrm{262)}(\mathrm{am} \mathrm{B} 262$ is the closest mutation to the amino-terminal end of the known $38 \mathrm{am}$ ). After intermediate culture at low multiplicity, I examined the trypsin resistance of isolated plaques of $\mathrm{am}^{+}$recombinants. The results (Table 6) provide evidence for the location of the ptr mutation near the carboxy-terminal end of gene 37 and probably close to the marker NG 475 .

\section{DISCUSSION}

The properties and assembly of the long tail fibres of T4 have been extensively studied (for reviews, see Wood \& Bishop, 1973; Wood et al., 1972). The remote part of the distal arm of the long tail fibres, where the mutation(s) studied in this paper map(s), has the property of recognizing bacterial receptors (Simon \& Anderson, 1967; Prehm et al., 1976). It has many 


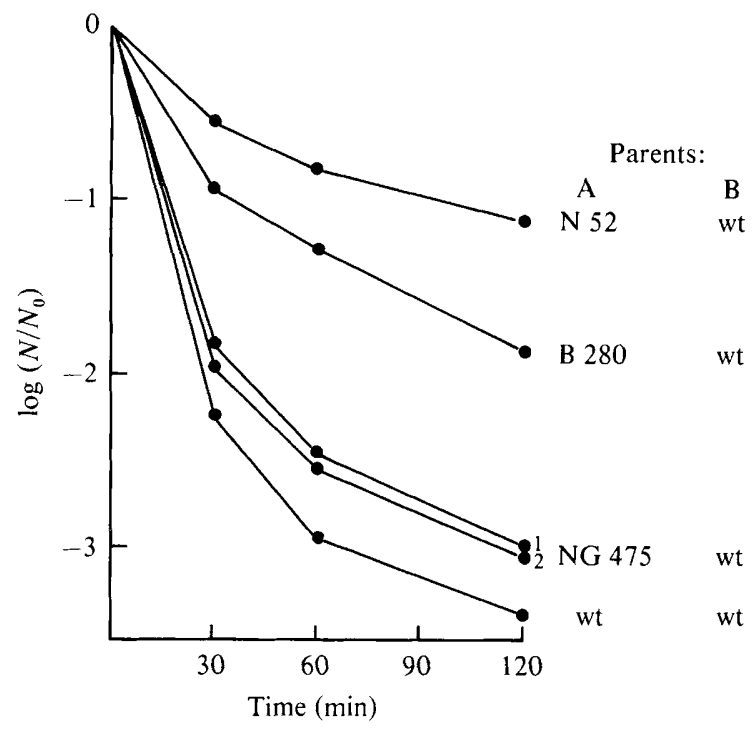

Fig. 7. Complementation of thermosensitive double mutants by wild type. Double mutants ptr and ts 37 were isolated as revertants of the amber mutant as described; under non-permissive conditions $\left(41^{\circ} \mathrm{C}\right)$, they were complemented by wild-type T4 in an experiment similar to that described in Fig. 6.ts revertants are named by the amber they come from. The thermosensitive revertant from $37 \mathrm{am}$ NG 475 is as susceptible to trypsin as the wild-type. Each point is the average of three experiments.

Table 6. Three-factor cross

Several double mutants carrying the ptr mutation and different am mutations in gene 37 were crossed with 38 ( $a m$ B 262). After intermediate culture at low multiplicity, the trypsin resistance of isolated plaques of $\mathrm{am}^{+}$recombinants was examined.

$\begin{array}{cccccc}\text { am mutant } \ldots & 36(a m \text { E 1) } & 37(a m \text { B 34) } & 37(a m \text { N 52) } & 37 \text { (am B 280) } & 37 \text { (am NG 475) } \\ a^{+}-p t r / w t \text { total } & 85 / 200 & 56 / 100 & 55 / 200 & 19 / 99 & 9 / 100\end{array}$

peculiarities and this quarter of gp 37 (which includes the carboxy-terminal end) does not have the morphological, biological and biophysical properties of the rest of the molecule (Beckendorf, 1973; Beckendorf et al., 1973). Recent DNA sequencing of gene 37 does not invalidate Beckendorf's discoveries and the hypotheses derived from them (Oliver and Crowther, 1981).

The inactivation reaction. The reversibility of temperature action (Table 3) associated with the abrupt thermal transition (Table 4) strongly suggests the involvement of reversible protein denaturation. Conversely, protease inhibition during T4 infection has been described (Simon $e t$ al., 1978). Beckendorf (1973) has proposed a $\gamma$-helical structure for the last quarter of the distal arm. However, this author pointed out that the structure lacked the instability predicted for this conformation. Demonstration of thermal instability would confirm Beckendorf's hypothesis.

Clipping gives rise to only one band on gels (Figs 3 and 4). This means that the two polypeptide chains constituting the distal arm (Ward \& Dickson, 1971) must be cut at the same site, since the two gp 37 are oriented linearly and parallel in the distal arm (Beckendorf, 1973), and Oliver \& Crowther's (1981) data do not provide two close sites which could fit our SDSPAGE measurements. This would also confirm Beckendorf's model. Both the mechanism of denaturation and correct spontaneous renaturation deserve further consideration.

Another surprising observation is the difference between the slope of the p.f.u..inactivation curve and that of the SDS-PAGE clipping curve (Fig. 4). Since the ptr mutation, located in gene 37 , prevents p.f.u. inactivation, I am led to suspect that trypsin provokes an inactivation that escapes detection by SDS-PAGE. Only Arg 1024 of Oliver \& Crowther's (1981) sequence can fit the data: the reaction would liberate a dipeptide, Leu-Ala-COOH, an hypothesis worth testing. The other site of denaturation, with a probability ten times lower, could be at Lys 945 or 
Arg 954. These two different probabilities of denaturation are good arguments in favour of at least two distinct mutations, as will be discussed below.

Another unanswered question is the reason why the curves presented here demonstrate firstorder kinetics in spite of the fact that phage T4 has six long fibres, three of which are necessary for phage adsorption (Wood \& Henninger, 1969; Crawford \& Goldberg, 1980): one would expect at least a three-hit phenomenon. Several hypotheses could explain the observation, among which I should mention: (1) the formation of a new, sensitive, cooperative structure at $60{ }^{\circ} \mathrm{C}$; (2) that the clipping of only one fibre could perturb the reversible step of adsorption (Crawford \& Goldberg, 1977); (3) that three fibres only are normally involved in phage T4 adsorption. Further studies are necessary to distinguish between these hypotheses.

Genetical results. Genetics is not easy because of the complexity of the region of the genome coding for tail fibre proteins, the polarity of the $36,37,38$ region and, in the case of my mutant, the phenotypic dominance. The differences in behaviour of gene 37 double mutants deserve some comment. The intermediate sensitivity of the offspring of coinfection by wt and ptr-36 $(a m \mathrm{E} 1)$ is clearly explained by polarity. On the other hand, the same phenomenon is less easy to understand for am B 34 and am N 52, since the mutants are not leaky. I compared the trypsin sensitivity of phage particles at $30 \mathrm{~min}$ and $60 \mathrm{~min}$ after coinfection (data not shown): the differences were too small to explain the differences in trypsin sensitivity. Polarity does not explain the results, since the closer to the carboxy-terminal the mutants are, the more sensitive the offspring. An explanation can be found either in abnormalities of recombination (which have been described in this region: Fisher \& Bernstein, 1970) or in intragenic complementation, of which gp 37 provides one of the best instances (Bernstein et al., 1965).

Several facts suggest that my ptr mutant might carry more than one mutation. First, the way it has been selected implies that it is not a single-step mutant. The different slopes for p.f.u. inactivation and gp 37 clipping suggest two different, distant, regions of denaturation. Secondly, the behaviour of some mutants in genetical experiments argues in favour of a double mutation: particularly the observation that the double mutant ptr-am B 280 gave the sensitive response, even though the $t s$ derived from it did not.

In conclusion, the ptr mutation(s) map(s) in gene 37, but accurate numbering and location of the mutation(s) await DNA sequencing of this part of gene 37 of the ptr mutant.

The experimental observations contribute to the outlining of two biological entities, each being part of the definition of the other: a specific inactivation reaction and the corresponding resistant mutant.

The practical interest of the ptr mutation is obvious: it suggests a new way of purifying phage $\mathrm{T} 4$ free of dispensable proteins; it produces a new frame of reference for the definition of the electrophoretic pattern of T4 proteins, and indicates which are minor and which dispensable proteins; it provides a means of detection of any protease active at $60^{\circ} \mathrm{C}$. From the theoretical viewpoint, I feel the most surprising fact is that modification of a single protein causes phage inactivation under the conditions defined in this paper.

I gratefully acknowledge Professor Edouard Kellenberger's hospitality in his laboratory, Professor Tom Bickle's interest and careful reading of the manuscript and Professor Richard Epstein's stimulating discussions about genetics. I thank the staff of the Microbiology Department for their friendly welcome which made my stay in Basel so pleasant. Special thanks are due to $\mathrm{M}$. Wurtz for allowing me to quote as a personal communication some of his as yet unpublished results.

This work was supported by the Swiss National Science Foundation (3.755.80) and by the Direction Générale de la Recherche Scientifique et Technique (MRM 78/7.1086). The author is a permanent research worker of the Centre National de la Recherche Scientifique, 15 quai Anatole France, 75700 Paris, France.

\section{REFERENCES}

ADAmS, M. H. (1959). Bacteriophages. New York: Wiley Interscience.

Arscott, P. G. \& Goldberg, E. B. (1976). Cooperative action of the $\mathrm{T} 4$ tail fibers and base plate in triggering conformational change and in determining host range. Virology 69, 15-22.
BECKENDORF, S. K. (1973). Structure of the distal half of the bacteriophage T4 tail fiber. Journal of Molecular Biology 73, 37-53.

BeCKendorf, S. K., Kim, J. S. \& Lielausis, I. (1973). Structrure of bacteriophage T4 genes 37 and 38 . Journal of Molecular Biology 73, 17-35. 
Bernstein, H., Edgar, R. S. \& Denhardt, G. H. (1965). Intragenic complementation among temperature sensitive mutants of bacteriophage T4 D. Genetics 51, 987-1002.

Cleveland, D. W., Fisher, S. G., Kirschner, M. W. \& Laemmli, U. K. (1977). Peptide mapping by limited proteolysis in sodium dodecyl sulphate analysis by gel electrophoresis. Journal of Biological Chemistry 252, 1102-1106.

Crawford, J. T. \& Goldberg, E. B. (1977). The effect of base plate mutants on the requirement for tail fiber binding for irreversible adsorption of bacteriophage T4. Journal of Molecular Biology 111, 305-313.

Crawford, J. T. \& Goldberg, E. B. (1980). The function of tail fibers in triggering base plate expansion of bacteriophage T4. Journal of Molecular Biology 139, 679-690.

DAwES, J. (1975). Characterization of the bacteriophage receptor site. Nature, London 256, 127 128.

Fisher, K. M. \& Bernstein, H. (1970). Deficiency of double mutant recombinants in crosses of phage T4. Molecular and General Genetics 106, 139-150.

GoldBerG, A. L. (1972). Correlation between rates of degradation of bacterial proteins in vivo and their sensitivity to proteases. Proceedings of the National Academy of Sciences of the United States of America 69, 2640-2644.

GoldBerG, A. L. \& Dice, J. F. (1974). Intracellular protein degradation in mammalian cells: part 1 . Annual Review of Biochemistry 43, 835-869.

GoldberG, A. L. \& ST JOHN, A. C. (1976). Intracellular protein degradation in mammalian and bacterial cells: part 2. Annual Review of Biochemistry 45, 747 803.

KAO, S. H. \& McClain, W. H. (1980). Base plate protein of bacteriophage T 4 with both structural and lytic functions. Journal of Virology 34, 95-103.

Kellenberger, E., Bolle, A., Boy de la Tour, E., Epstein, R. H., Franklin, N. C., Jerne, N. K., Reale-Scafati, A. \& Sechaud, J. (1965). Functions and properties related to the tail fibers of bacteriophage T4. Virology 26, 419-440.

KING, J. \& LaemmLI, U. K. (1971). Polypeptides of the tail fibers of bacteriophage T4. Journal of Molecular Biology 62, 465-477.

Oliver, D. B. \& Crowther, R. A. (1981). DNA sequence of the tail fiber gene 36 and 37 of bacteriophage T4. Journal of Molecular Biology 153, 545-568.
Prehm, P., Jann, B., JanN, K., Schmidt, G. \& Stirm, S. (1976). On a bacteriophage T3 and T4 receptor region within the cell wall lipopolysaccharide of Escherichia coli B. Journal of Molecular Biology 101, 277-281.

Showe, M. K., Isobe, E. \& ONorato, L. (1976). Bacteriophage T4 prehead proteinase. 1. Purification and properties of bacteriophage enzyme which cleaves the capsid precursor proteins. Journal of $\mathrm{Mo}$ lecular Biology 107, 35-54.

Simon, L. D. \& ANDERson, T. F. (1967). The infection of Escherichia coli by T2 and T4 bacteriophages as seen in the electron microscope. 1. Attachment and penetration. Virology 32, 279-297.

Simon, L. D., TomczaK, K. \& St John, A. C. (1978). Bacteriophages inhibit degradation of abnormal proteins in E. coli. Nature, London 275, 424428.

Stahl, F. W., Crasemann, J. M., Yegian, C., Stahl, M. M. \& NaKaTA, A. (1970). Co-transcribed cistrons in bacteriophage T4. Genetics 64, 157-170.

TERZAGHI, E. (1971). Alternative pathways of tail fiber assembly in bacteriophage T4. Journal of Molecular Biology 59, 319-327.

To, C. M., Kellenberger, E. \& Eisenstark, A. (1969). Disassembly of T-even bacteriophage into structural parts and subunits. Journal of Molecular Biology 46, 493-511.

WARD, S. \& DICKSON, R. C. (1971). Assembly of bacteriophage T4 tail fibers. III. Genetic control of the major tail fiber polypeptides. Journal of Molecular Biology 62, 479-492.

Woop, W. B. \& Bishop, R. J. (1973). Bacteriophage T4 tail fibers: structure and assembly of a viral organelle. In Virus Research, pp. 303-324. Edited by C. F. Fox \& W. S. Robinson. New York: Academic Press.

WOOD, W. B. \& HENNINGER, M. (1969). Attachment of tail fibers in bacteriophage T4 assembly: some properties of the reaction in vitro and its genetic control. Journal of Molecular Biology 39, 603618.

Wood, W. B., Dickson, R. C., Bishop, R. J. \& Revel, H. R. (1972). Self-assembly and non-self-assembly in bacteriophage T4 morphogenesis. In The Generation of Subcellular Structures, pp. 25-59. Edited by R. Markham, J. B. Bancroft, D. R. Davies, D. A. Hopwood \& R. W. Horne. Amsterdam: NorthHolland Publishing Company. 